\title{
Targeted ToF-SIMS Analysis of Macrophage Content from a Human Cranial Triphasic Calcium Phosphate Implant
}

\author{
Per Malmberg, Viviana R. Lopes, Gry Hulsart Billström, Sara Gallinetti, Christopher Illies, \\ Lars Kihlström Burenstam Linder, and Ulrik Birgersson*
}

Cite This: ACS Appl. Bio Mater. 2021, 4, 6791-6798

Read Online

ACCESS |

山ll Metrics \& More

Article Recommendations

SI Supporting Information

ABSTRACT: Macrophages play a key role in determining the fate of implanted biomaterials, especially for biomaterials such as calcium phosphates ( $\mathrm{CaPs}$ ) where these cells play a vital role in material resorption and osteogenesis, as shown in different models, including clinical samples. Although substantial consideration is given to the design and validation of different $\mathrm{CaPs}$, relatively little is known about their material-cell interaction. Specifically, the intracellular content of different $\mathrm{CaP}$ phases remains to be assessed, even though CaP-filled macrophages have been observed in several studies. In this study, 2D/3D ToF-SIMS imaging and multivariate analysis were directly applied on the histology samples

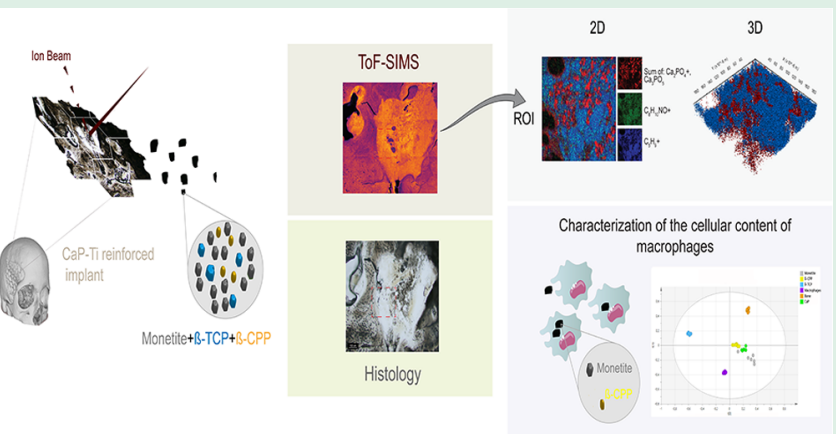
of an explant to reveal the content of macrophages. The cellular content of the macrophages was analyzed to distinguish three $\mathrm{CaP}$ phases, monetite, beta-tricalcium phosphate, and pyrophosphate, which are all part of the monetite-based $\mathrm{CaP}$ implant composition under study. ToF-SIMS combined with histology revealed that the content of the identified macrophages was most similar to that of the pyrophosphate phase. This study is the first to uncover distinct $\mathrm{CaP}$ phases in macrophages from a human multiphasic $\mathrm{CaP}$ explant by targeted direct cell content analysis. The uncovering of pyrophosphate as the main phase found inside the macrophages is of great importance to understand the impact of the selected material in the process of biomaterial-instructed osteogenesis.

KEYWORDS: calcium phosphate, pyrophosphate, cranial implant, macrophages, ToF-SIMS

\section{INTRODUCTION}

Calcium phosphates ( $\mathrm{CaPs}$ ) remain as the synthetic biomaterials of choice for bone regeneration and repair ${ }^{1-7}$ owing to their chemical homology with the inorganic part of the bone and the ability to promote bone formation while slowly degrading. ${ }^{1-7,8}$

The CaP material degradation is achieved via mechanical breakdown, passive chemical dissolution, or active cellmediated resorption via macrophages, monocytes, multinucleated giant cells, and osteoclasts. ${ }^{9-13}$ While the material degradation gradually occurs, osteoblasts are attracted to the region and initiate bone formation. Osteoblasts synthesize and secrete the bone matrix and deposit calcium to form new bone. The newly formed bone is resorbed by osteoclasts (bone modeling), shaping the bone and ensuring its optimal function. ${ }^{12,14}$

During material-mediated bone formation and regeneration, macrophages and their main precursor, monocytes, are among the first cells attracted to the implant. ${ }^{15-20}$ Macrophages are known as "true" phagocytes responsible for the internalization and subsequent digestion of exogenous and endogenous contents. $^{15,20,21}$ Even though CaP-filled macrophages have been observed in various in vivo models following months to years after implantation, ${ }^{1,2,4,6,22-25}$ the nature of the content engulfed still lacks substantial evidence. Given that macrophages have been suggested to play an important role in biomaterial-instructed osteogenesis, studying their interaction with various $\mathrm{CaP}$ phases might yield valuable insights into the underlying mechanism of action. ${ }^{16,17,26,27}$

Time-of-flight secondary ion mass spectrometry (ToFSIMS) has previously been used to detect lipids and organic materials at implant surfaces to characterize calcium phosphate phases in powders ${ }^{28,29}$ and at implant surfaces and interfaces to ascertain inorganic information from calcium- and phosphatecontaining materials. ${ }^{30-32}$ Additionally, the high lateral resolution of ToF-SIMS allows for intracellular information to be obtained. ${ }^{33-35}$

In order to identify the content of macrophages, we aimed to evaluate if ToF-SIMS could be employed to characterize the

Received: May 6, 2021

Accepted: August 9, 2021

Published: August 20, 2021 
macrophage content concerning three $\mathrm{CaP}$ phases, monetite, beta-tricalcium phosphate $(\beta$-TCP), and beta-calcium pyrophosphate $(\beta$-CPP), in a clinically retrieved titaniumreinforced $\mathrm{CaP}$ cranial implant 31 months after implantation.

\section{EXPERIMENTAL SECTION}

2.1. Material Production and Characterization. Four different $\mathrm{CaP}$ compositions were synthesized for the experiment: beta-calcium pyrophosphate $(\beta$-CPP) produced by decomposing di-calcium phosphate dihydrate (DCPD, brushite, Acros Organics) at 1100 ${ }^{\circ} \mathrm{C}$; beta-tricalcium phosphate $(\beta$-TCP) prepared through a solidstate reaction of a powder mixture of brushite (Acros Organics) and calcium carbonate (Acros Organics) at $1100{ }^{\circ} \mathrm{C}$; brushite synthesized by mixing at a $\mathrm{L} / \mathrm{P}$ ratio of 0.22 a $50: 50$ mixture of monocalcium phosphate monohydrate (MCPM, Scharlau): $\beta$-TCP (Degradable Solutions AG) with a citric acid aqueous solution $(0.5 \mathrm{M})$, which was set in water for $24 \mathrm{~h}$ and then dried at room temperature; and monetite obtained by autoclaving the abovementioned brushite; a $\mathrm{CaP}$ mixture of the implant was fabricated by mixing MCPM with a mixture of $\beta$-TCP and $\beta$-CPP as pre-mixed cements. ${ }^{22}$

The phase compositions of the different calcium phosphates were ascertained through X-ray diffraction (XRD; Aeris Panalytical, Malvern for Monetite, $\beta$-TCP, and $\beta$-CPP and D8 Advance, Bruker AXS $\mathrm{GmbH}$ for implant calcium phosphate composition) with a theta-theta $(2 \theta)$ setup with Ni-filtered $\mathrm{Cu}-\mathrm{K}$ irradiation. Rietveld refinements were applied to perform a quantitative phase composition analysis. BGMN software (www.bgmn.de) was used with Profex as the user interface. ${ }^{36}$ Crystalline models were taken from the Profex database based on literature references for $\beta$-CPP (PDF\# 04-0093876), ${ }^{37} \beta$-TCP (PDF\# 04-010-4348), ${ }^{38}$ and monetite (PDF\# 04009-3755). ${ }^{39}$ No other phases were identified in the diffraction patterns.

2.2. Sample Processing. 2.2.1. Clinical Retrieval. A 30-year-old woman was diagnosed with osseous sphenoidal wing meningioma in November 2014 and subsequently underwent tumor resection and cranial reconstruction with a titanium-reinforced $\mathrm{CaP}$ implant (OssDsign Cranial PSI). A period of 31 months after implantation, the implant was explanted due to tumor progression into the orbit, which required surgical intervention. Except for the tumor, the patient is in good general condition with no immunodeficiency. The patient provided signed informed consent, and the review was conducted under Regional Ethics Committee approval, Stockholm Dnr 2017/ 251031.

2.3. Sample Evaluation. 2.3.1. Computed Tomography (CT). The subject's post-operative and follow-up CT scans (Discovery CT750 HD, GE Healthcare, Wisconsin, USA) were reviewed in terms of implant remodeling and bone formation.

2.3.2. Histology. 2.3.2.1. Histological Processing. The cranial sample was preserved in $10 \%$ neutral buffered paraformaldehyde at the time of explantation. The implant was later dehydrated in alcohol solutions of increasing concentration $(60,80,95 \%$, and $2 \times 99.9 \%)$ and cleared in xylene. The material samples and the cranial implant were infiltrated in increasing concentration of resin, using the Technovit 7200 (Kulzer Exakt, Histolab, Gothenburg Sweden), mixed with $99.9 \%$ ethanol in steps of 30:70, 50:50, 7:30, 100, and $100 \%$. Histological sections were prepared using a microcutting and microgrinding system (EXAKT System, Advanced Technologies $\mathrm{GmbH}$, Germany), with the thickness of each section ranging between 15 and $35 \mu \mathrm{m}$. Prior to staining, the section was immersed in $30 \% \mathrm{H}_{2} \mathrm{O}_{2}$ (Sigma-Aldrich, Stockholm, Sweden) for 6 min to etch the surface of the specimens and then immersed in $12 \%$ acetic acid for 30 $s$ to decalcify the surface slightly. Thereafter, the section was stained for 30 min with modified Paragon consisting of $0.01 \%$ Toluidine Blue $\mathrm{O}$ and $0.02 \%$ borax in distilled water. Subsequently, the slide was exposed to $0.005 \%$ basic fuchsine in $95 \%$ ethanol for $30 \mathrm{~s}$ and finally with $0.1 \%$ Safranin $\mathrm{O}$ in distilled water for $5 \mathrm{~min}$. Between all steps of pretreating and staining, the slide was rinsed in tap water twice and wiped dry. All stains and solutions were obtained from Histolab, Gothenburg Sweden.
2.3.2.2. Analysis. Histological analysis was performed to identify macrophages, osteoblast cells, osteoclasts, osteocytes, red blood cells and blood vessels, newly formed bone, and adipose tissue by two expert pathologists from different institutions (Karolinska Institute and NAMSA) before and after staining with modified Paragon. Images were observed and captured using a $40 \times$ objective under an optical microscope.

2.4. TOF-SIMS. The different $\mathrm{CaP}$ phases $(\beta$-CPP, $\beta$-TCP, and monetite) and samples of human tissue cranial explants were analyzed with ToF-SIMS on a TOF.SIMS 5 instrument (ION-TOF GmbH, Münster, Germany) equipped with a Bismuth-cluster ion gun as the primary ion source and a C60 ion source for sputtering and depth profiling. Different fields of view $(n=5)$ ranging from $60 \times 60$ to 500 $\times 500 \mu \mathrm{m}$ were analyzed in the two-dimensional (2D) mode with the following settings: pulsed primary ion beam $\left(\mathrm{Bi}_{3}{ }^{+}, 0.34 \mathrm{pA}\right.$ at $\left.25 \mathrm{keV}\right)$, the so-called high-bunched mode, ${ }^{40}$ a focus of approximately $2 \mu \mathrm{m}$, and a mass resolution of approx. $M / \Delta M=5000 \mathrm{fwhm}$ at $\mathrm{m} / z 500$. Selected areas were also analyzed in $2 \mathrm{D}$ with the delayed extraction mode $^{41}$ with a focus of approx. $400 \mathrm{~nm}$ and an achieved mass resolution of approx. $M / \Delta M=4000 \mathrm{fwhm}$ at $\mathrm{m} / z 500$. The maximum ion dose density of $\mathrm{Bi}_{3}{ }^{+}$was kept at $2 \times 10^{11}$ ions $\mathrm{cm}^{-2}$ and therefore below that of the static limit, that is, $1 \times 10^{13}$ ions $\mathrm{cm}^{-2}$, to avoid causing surface damage to allow subsequent histological analysis.

Three-dimensional (3D) imaging and depth profiling was performed with the pulsed $\mathrm{Bi}_{3}{ }^{+}$gun $(0.34 \mathrm{pA})$ and a $20 \mathrm{keV} \mathrm{C}{ }_{60}{ }^{2+}$ beam with a current of $0.2 \mathrm{nA}$ in the non-interlaced mode. The ion dose for $\mathrm{C}_{60}{ }^{2+}$ ranged from $1 \times 10^{14}$ to $9 \times 10^{14}$ ions $\mathrm{cm}^{-2}$.

Low-energy electrons were used for charge compensation during analysis. All spectra were acquired and processed with Surface Lab software (version 7.0, ION-TOF GmbH, Münster, Germany).

2.5. Multivariate Analysis. The ToF-SIMS spectral data were evaluated by multivariate analysis. The search peaks function in Surface Lab software was used on spectra from each material and region of interest (ROI) spectra obtained from macrophages and bone. Peaks that had $>100$ counts, a signal to noise ratio of $>3$, and a width of $0.8 \mathrm{Da}$ were selected. In total, more than five replicate measurements from each of the reference materials and six ROI spectra from macrophages and bone were selected. The data set included 330 positive ions that were subjected to principal component analysis (PCA) in SIMCA (version 15.0, Umetrics, Umea, Sweden). The spectra were pretreated by mean centering and Pareto scaling. No peaks except $[\mathrm{H}]^{+}, m / z 1$, were eliminated from the PCA analysis.

\section{RESULTS}

3.1. Clinical Retrieval. The cranial explant is composed of a CaP biomaterial with hexagonal-shaped tiles reinforced with a medical-grade 23 titanium mesh (Figure 1A). Prior to explantation, clinical CT revealed bone ingrowth and bone formation on and inside the tiles and bridging bone formation in the intertile spaces (Figure 1B). Perioperative gross inspection, 31 months after implantation, revealed the formation of normal vascularized bone and an implant that was well-integrated with the recipient's bone (Figure 1C). The analysis was directed to the ROI between tiles where the new bone had bridged the previously empty space (Figure 1D), evident in both $\mathrm{CT}$ and perioperative observations, which was confirmed by histology (Figure 1E). No tumor infiltration or tumor-infiltrating lymphocytes were noted in the ROI.

3.2. Post-implantation Imaging of the CaP Implant. 3.2.1. Characterization of the Reference Materials. The phase composition of the reference $\mathrm{CaP}$ materials was quantified with XRD: the $\beta$-CPP was pure at $97 \%$ with $3 \%$ impurity of $\beta$-TCP; $\beta$-TCP was pure at $97 \%$ with $2 \%$ impurity of hydroxyapatite and $1 \% \beta$-CPP; and monetite was pure at $97 \%$ with 2 and $1 \%$ impurity of $\beta$-TCP and $\beta$-CPP, respectively. The XRD pattern for each present material phase is depicted in Figure 2. 


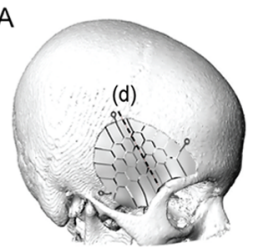

B

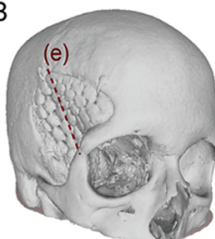

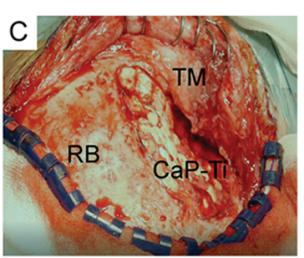

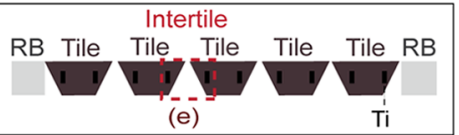

E

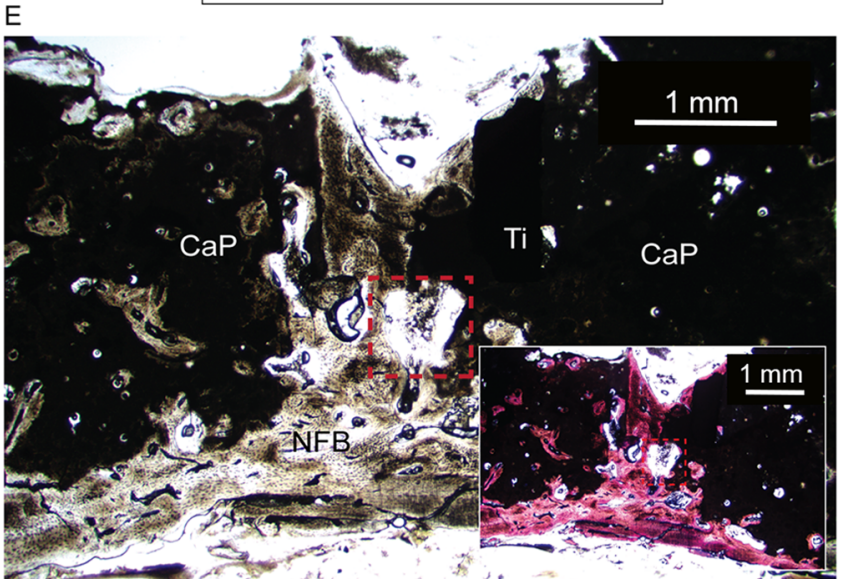

Figure 1. Clinically retrieved specimen. (A) Schematic overview of the subject's skull and implant prior to implantation. (B) CT scan prior to implant retrieval. The dotted red line marks the location of the histology section. (C) Perioperative image of the $\mathrm{CaP}-\mathrm{Ti}$ reinforced implant. (D) Schematic overview of the position of the histological section. (E) Histology section prior to staining with clear bone bridging between the $\mathrm{CaP}$ tiles of the implant and after staining. Illustration of the ROI selected for analysis (scale bar, $1 \mathrm{~mm}$ ). The dotted red square marks the ROI. Acronyms: CaP: calcium phosphate, $\mathrm{CaP}-\mathrm{Ti}$ : titanium-reinforced $\mathrm{CaP}$ cranial implant, NFB: newly formed bone, RB: recipient bone, TM: temporal muscle, and Ti: titanium.

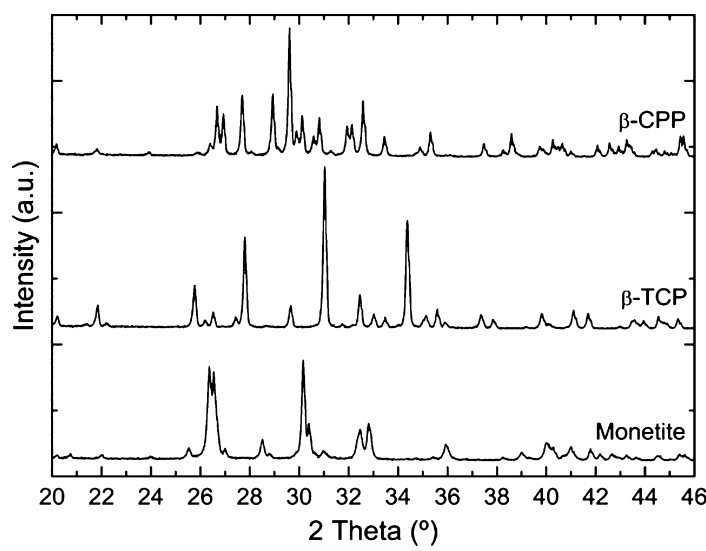

Figure 2. Characterization of different phases. XRD patterns for pure $\beta$-CPP, $\beta$-TCP, and monetite reference samples. The patterns correspond to the PDF reference patterns for $\beta$-CPP (PDF\# 04009-3876), $\beta$-TCP (PDF\# 04-010-4348), and monetite (PDF\# 04009-3755).

The implant ( $\mathrm{CaP}$ prior to implantation) showed a mixture of CaPs: monetite (84\%), $\beta$-TCP (9\%), and $\beta$-calcium pyrophosphate $(\beta$-CPP, $7 \%)$. Additionally, the reference materials were analyzed with TOF-SIMS. Representative mass spectra for the different $\mathrm{CaP}$ phases, monetite, $\beta$-TCP, and $\beta$-CPP, can be seen in Figure S1. All CaP spectra appear relatively similar with peaks from calcium oxide and calcium hydroxide, $[\mathrm{CaO}]^{+}$and $[\mathrm{CaOH}]^{+}$and different $\mathrm{Ca}_{\mathrm{x}} \mathrm{P}_{\mathrm{y}}$ species, such as $\left[\mathrm{Ca}_{2} \mathrm{PO}_{4}\right]^{+}$and $\left[\mathrm{Ca}_{3} \mathrm{PO}_{5}\right]^{+}$clearly visible.

3.3. Histology. Histological analysis verified the transformation of the $\mathrm{CaP}$ into viable woven and lamellar bone with apparent bone bridging between tiles (Figure 3). Bone had

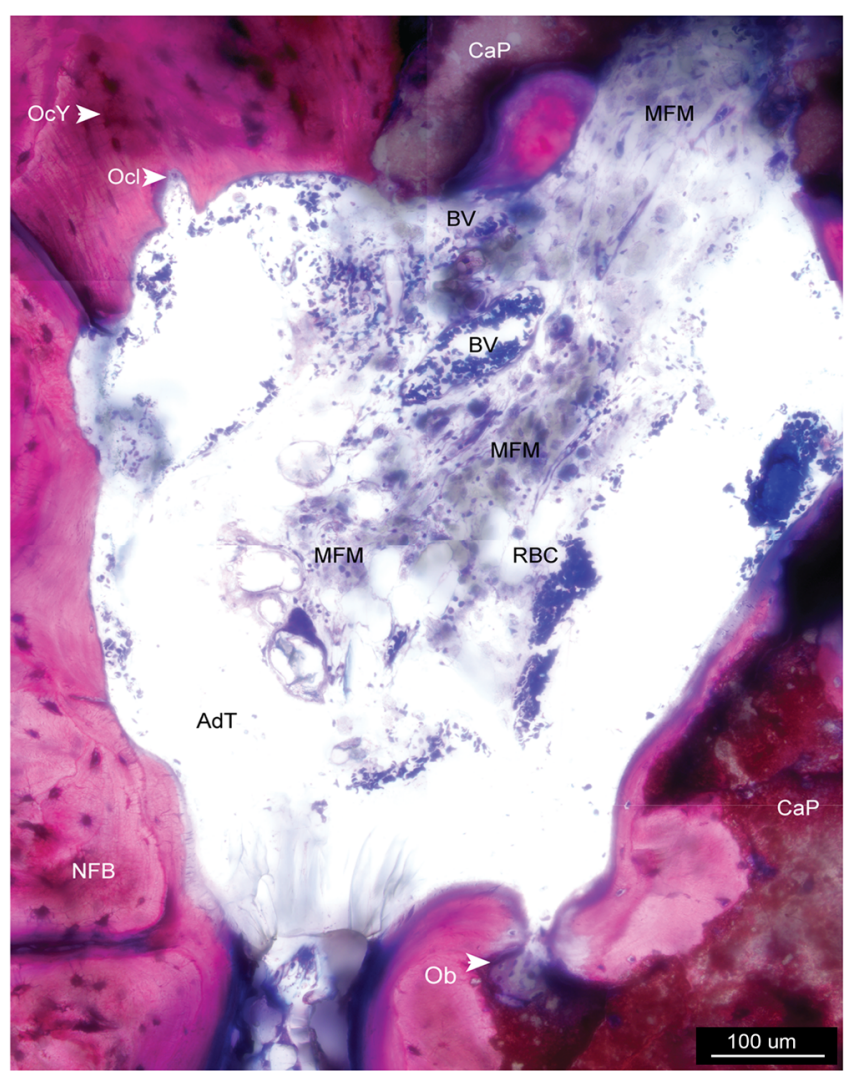

Figure 3. Macrophages within adipose compartments containing blood vessels surrounded by the newly formed bone. Histological image of the ROI (Figure 1E) in the intertile space of the retrieved titanium-reinforced $\mathrm{CaP}$ cranial implant using modified Paragon. Bone formation was registered on the $\mathrm{CaP}$ material with visible osteocytes, osteoblasts, and osteoclasts. One osteoclast is observed remodeling the newly formed bone. MFMs were found within adipose compartments containing blood vessels surrounded by newly formed bone. Acronyms: AdT: adipose tissue, BV: blood vessel, CaP: calcium phosphate, MFM: material-filled macrophages, NFB: newly formed bone, RB: recipient bone, Ob: osteoblasts, Ocl: osteoclasts, OcY: osteocytes, RBC: red blood cells, and Ti: titanium. (Scale bar, 100 $\mu \mathrm{m})$.

formed directly on the $\mathrm{CaP}$ and infiltrated its porous structure. Osteoblasts $(\mathrm{Ob})$, osteoclasts $(\mathrm{Ocl})$, osteocytes $(\mathrm{OcY})$, and material-filled macrophages (MFM) were detected. Macrophages were found within compartments with adipose tissue and blood vessels surrounded by newly formed bone.

3.4. ToF-SIMS Analysis. The specific content of macrophages found in the $\mathrm{CaP}-\mathrm{Ti}$ explant regarding the three $\mathrm{CaP}$ phases, monetite, $\beta$-TCP, and $\beta$-CPP, was investigated. The ROI selected was at the intertile spaces of the explant $\mathrm{CaP}$ tiles (Figure 4), where bridging of tiles with newly formed bone was observed and macrophages were commonly identified. 

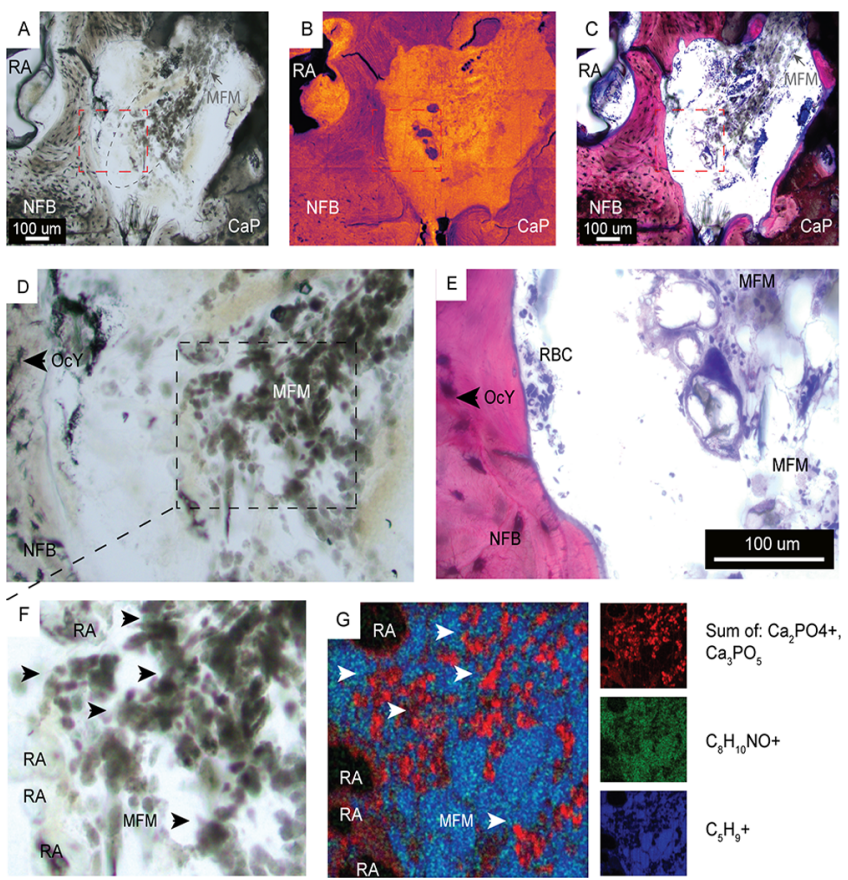

Sum of: $\mathrm{Ca}_{2} \mathrm{PO} 4$ $\mathrm{Ca}_{3} \mathrm{PO}_{5}$

$\mathrm{C}_{8} \mathrm{H}_{10} \mathrm{NO}+$

$\mathrm{C}_{5} \mathrm{H}_{9}+$

Figure 4. Histology and ToF-SIMS imaging of the intertile space. (A) Light microscopy image of the intertile space in the unstained sample (scale bar, $100 \mu \mathrm{m}$ ). (B) Corresponding TOF-SIMS total ion images (field view of $200 \times 200 \mu \mathrm{m}$ ). (C) Light microscopy image of the intertile space after modified Paragon staining (scale bar, $100 \mu \mathrm{m}$ ). (D) Magnification of the histology sample with MFM in the ROI (40× magnification) and (E) stained histology. (F) Higher magnification of macrophages filled with the $\mathrm{CaP}$ material in the ROI. (G) ToF-SIMS ion overlay image $\left(200 \times 200 \mu \mathrm{m}^{2}\right)$ showing cell content as highlighted by signals of $\mathrm{Ca}_{2} \mathrm{PO}_{4}$ and $\mathrm{Ca}_{3} \mathrm{PO}_{5}$ in red and DNA marker $\left(\mathrm{C}_{8} \mathrm{H}_{10} \mathrm{NO}\right)$ at $m / z 136.1$ in green superimposed on the ion signal from a general lipid fragment from cell membranes $\mathrm{C}_{5} \mathrm{H}_{9}$ in blue. The dashed red line represents the ROI. Acronyms: CaP: calcium phosphate, MFM: material-filled macrophages, NFB: newly formed bone, OcY: osteocytes, RA: resin artifact, and RBC: red blood cells.

Histology (Figure 4A,C) was compared to ToF-SIMS 2D total ion images (Figure 4B). Similar bone morphology and composition were visualized with ToF-SIMS, as was seen in histology. Macrophages in the explanted material identified by histological screening of the unstained material (Figure $4 A, D, F$ ) and, subsequently, of the stained sample (Figure 4C,E,F) were analyzed by ToF-SIMS 3D imaging, as shown in Figure 4G. Higher magnification of macrophages filled with the $\mathrm{CaP}$ material in the ROI can be seen in Figure 4F. The MFMs previously detected showed ion signals for the nucleus $\left(\left[\mathrm{C}_{8} \mathrm{H}_{10} \mathrm{NO}\right]^{+}\right)$and lipids $\left(\left[\mathrm{C}_{5} \mathrm{H}_{9}\right]^{+}\right.$and $\left.\left[\mathrm{C}_{5} \mathrm{H}_{15} \mathrm{PNO}_{4}\right]^{+}\right)$ associated with cell membranes distinctive for cells (Figure 4G and additional information in Figure S3). These data corroborate with typical morphology and cell dimensions of macrophages from histological findings.

The macrophage content was isolated by ROI analysis of the $3 \mathrm{D}$ chemical imaging data and compared to spectra from the $\mathrm{CaP}$ phases, monetite, $\beta$-TCP, and $\beta$-CPP, and ROIs from the bone and $\mathrm{CaP}$ in the implants after PCA (Figure 5). All components and individual loadings are shown in the Supporting Information, Figure S2.

Principal component $t[1]$ mostly captures differences in the salt content, that is, $m / z 22.9$ and 38.9, reflecting the differences between implanted (organic and inorganic) versus

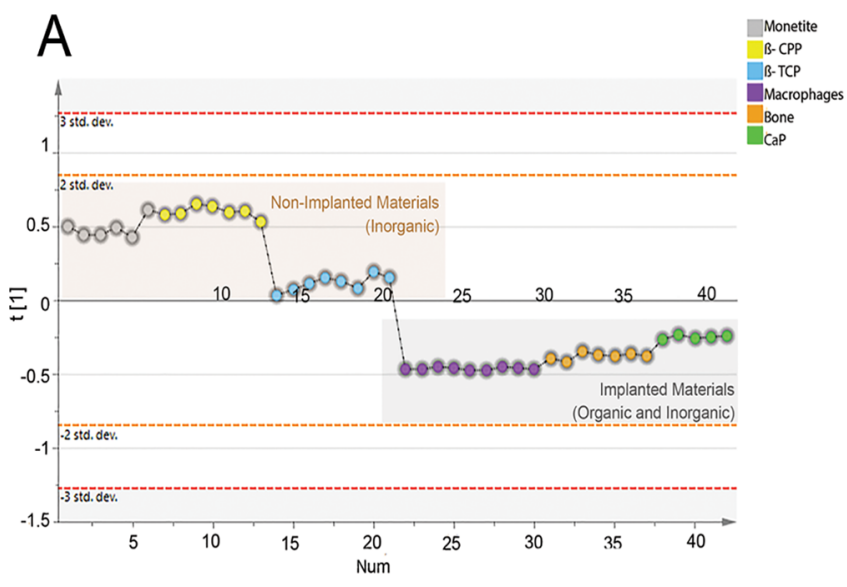

R2X[1] $=0.426$ Ellipse: Hotelling's T2 (95\%)

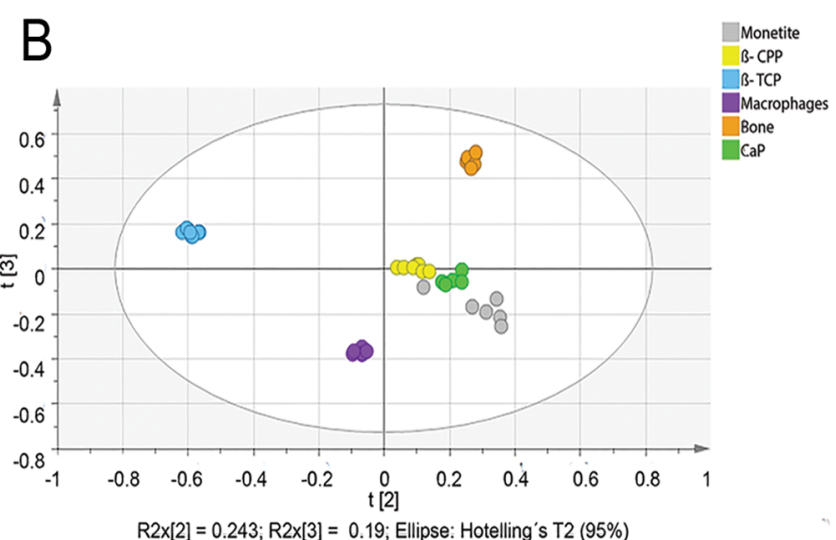

C

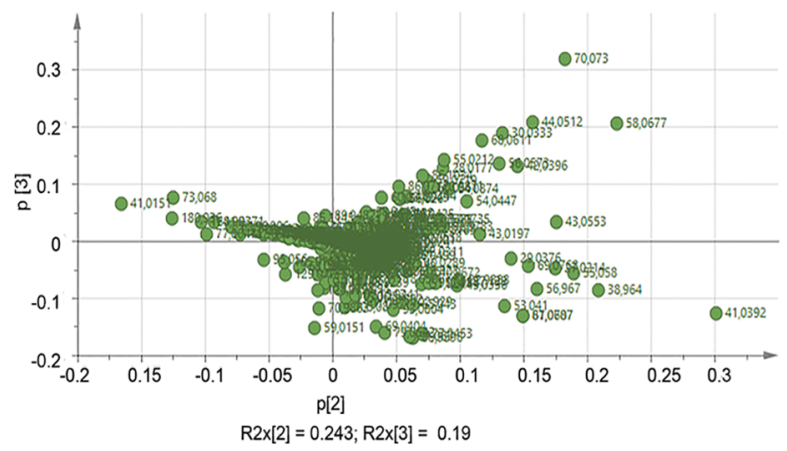

Figure 5. Multivariate analysis (PCA) comparing macrophage content with spectra from the different calcium phosphate $(\mathrm{CaP})$ phases and bone and $\mathrm{CaP}$ in the implants. (A) $1 \mathrm{D}$ score plot of $\mathrm{t}[1]$ showing the implanted (organic and inorganic) vs non-implanted materials (inorganic). Percent variation captured by $\mathrm{t}[1] 0.426 \%$. Ellipse: Hotelling's T2 (95\%). (B) Score biplot from $\mathrm{t}[2]$ vs $\mathrm{t}[3]$ highlighting sample grouping and showing the main similarity between the macrophage content and $\beta$-CPP. Circle: Hotelling's T2 (95\%). (C) Corresponding load plot for $\mathrm{t}[2]$ vs $\mathrm{t}[3]$. Gray: monetite, Yellow: $\beta$-CPP, Blue: $\beta$-TCP, Purple: macrophage cell content, Orange: bone in the implant, and Green: $\mathrm{CaP}$ from the implant.

non-implanted materials (inorganic), as shown in Figure 5A. As can be seen in the $x$-axis (Figure 5B), component $\mathrm{t}[2]$ reveals more relevant information where characteristic peaks from, for example, $\mathrm{Ca}_{x} \mathrm{P}_{y}$ can be found. Therefore, the results are presented in scores (Figure 5B) and loading plots (Figure 5D) associated with components $t[2]$ and $t[3]$. The score plot of $\mathrm{t}[2]$ versus $\mathrm{t}[3]$ reveals high similarity between the different 
$\mathrm{CaP}$ phases monetite (gray) and $\beta$-CPP (yellow) and the $\mathrm{CaP}$ reference (green) except the $\beta$-TCP phase (blue) (Figure 5B). The macrophage content (purple) can be seen to be mostly similar to that of the raw material $\beta$-CPP followed by monetite, while the bone sample (orange) lies further away from the macrophages and therefore is less similar to the content of the macrophages.

The PCA analysis could be confirmed by studying the individual spectra (Figure S1). The material trapped inside the macrophages (described in the histological findings) contained peaks matching the pattern from both monetite and $\beta$-CPP, with the main cell content being mostly similar to that of $\beta$ CPP. This was verified by calculating the ratio between $\frac{\mathrm{P}_{x} \mathrm{O}_{y}}{\mathrm{P}_{x} \mathrm{H}_{y} \mathrm{O}_{z}}$, that is, $\frac{\mathrm{P}_{2} \mathrm{O}_{2}+\mathrm{PO}_{2} \mathrm{H}}{\mathrm{Ca}_{2} \mathrm{PO}_{4}+\mathrm{Ca}_{3} \mathrm{PO}_{5}}$ species inside the cells and compared to different $\mathrm{CaP}$ phases ( $\beta$-CPP, $\beta$-TCP, and monetite) and samples of human tissue cranial explants (i.e., $\mathrm{CaP}$ and bone). The ratios are provided in Table 1 .

Table 1. Ratio between $\frac{\mathrm{P}_{2} \mathrm{O}_{2}+\mathrm{PO}_{2} \mathrm{H}}{\mathrm{Ca}_{2} \mathrm{PO}_{4}+\mathrm{Ca}_{3} \mathrm{PO}_{5}}$ Species for Macrophages, Different CaP Phases, and Samples of CaP and Bone

\begin{tabular}{ll} 
material & ratio \\
macrophages & 0.087 \\
$\beta$-CPP & 0.084 \\
$\beta$-TCP & 0.43 \\
monetite & 0.056 \\
$\mathrm{CaP}$ & 0.062 \\
bone & 0.16 \\
\hline
\end{tabular}

Furthermore, ToF-SIMS 3D imaging corroborated that (i) the $\beta$-CPP signal was from the intracellular content rather than a surface phenomenon and (ii) the $\beta$-CPP signal is consistent throughout the cell (Figure 6). Additional results can be found in the Supporting Information (Figure S3).

\section{DISCUSSION}

Several studies have revealed the presence of macrophages filled with the $\mathrm{CaP}$ material, which has been shown to play a role in bone formation, independent of the implantation time and location of the defect. ${ }^{2-4,6,8,22,25,42-44}$ In addition, it has always been assumed that the intracellular content of these macrophages is of the homogenous composition of the biomaterial chosen or accessible to cells in the biological milieu described. In this study, by applying a targeted $2 \mathrm{D} / 3 \mathrm{D}$ ToF-SIMS and multivariate analysis in combination with conventional histology, we investigated the cell content of the macrophages identified in a human cranial explant.

The $\mathrm{CaP}$ explant investigated contains monetite (84\%), $\beta$ TCP (9\%), and $\beta$-CPP (7\%); it could thus be assumed that a similar material composition might be found within the macrophages. However, based on the quantity of each $\mathrm{CaP}$ phase and its dissolution profiles in aqueous solutions and the cell digestion process, we hypothesized that the material found within the identified macrophages would be mostly $\beta$-CPP given that 31 months had passed since implantation.

By applying 2D/3D ToF-SIMS imaging and multivariate analysis, we confirmed the macrophage content to be most similar to that of $\beta$-CPP and, to a lesser extent, monetite. Noteworthy is that the implant contains only $6 \% \beta$-CPP in contrast to $84 \%$ monetite, and still, $\beta$-CPP was the main phase found intracellularly. This finding follows the passive solubility trends between the different $\mathrm{CaP}$ phases that we assumed earlier, that is, monetite is the most soluble phase followed by $\beta$-TCP and ending with the almost insoluble phase $\beta$-CPP. ${ }^{45,46}$ This remaining phase, $\beta$-CPP, seems to resist complete digestion by macrophages even after 31 months, which coincides with the study by $\mathrm{Wu}$ and Uskokovic ${ }^{47}$ They showed in vitro that $\beta$-CPP was substantially more retained by phagocytic cells as compared to amorphous $\mathrm{CaP}$, hydroxyapatite, and monetite when supplied individually. Furthermore, they observed that the cells consumed more of the monetite powder. The biological processes of phagocytic and enzymatic degradation, local variations in acidity, wettability and/or oxidative degradation are factors that contribute to the fate of CaPs inside the macrophages. ${ }^{15,48-50} \mathrm{CaP}$ hydrolysis can be facilitated with a more acidic milieu and the presence of digestive enzymes, which are characteristic settings found inside the organelles involved in the phagocytosis process within cells, such as macrophages. ${ }^{45,46,51}$ This $\mathrm{pH}$ variation will impact the dissolution of the different $\mathrm{CaP}$ phases and, consequently, the amount of the material found intracellularly. Despite monetite being the most soluble phases at physiological $\mathrm{pH},{ }^{52}$ the substantial amount (84\%) present in the $\mathrm{CaP}$ explant will mostly determine that monetite particles will be present in cells to a higher degree and more prone than other phases to be ingested by macrophages, which might explain the remaining presence of monetite in our findings. Although $\beta$-CPP and $\beta$-TCP share similar proportions in the implant ( $\beta$-TCP, $9 \%$, and $\beta$-CPP, $7 \%$ ), $\beta$-TCP is less likely to be found due to the higher solubility compared to that of $\beta$ CPP. ${ }^{45,46}$ Furthermore, when an oxidative degradation environment is present (i.e., in the presence of reactive oxidative species), either in low $\mathrm{pH}$ or not, some materials can also be susceptible to higher solubility and/or chemical bond cleavage. $^{48}$

The byproducts generated during the material phagocytosis can be either used or offloaded by macrophages to maintain a healthy metabolism. ${ }^{53}$ For instance, monetite, when inside the macrophages and under acidic conditions, will degrade to its hydrolysis products, that is, calcium $\left(\mathrm{Ca}^{2+}\right)$ and phosphate $\left(\mathrm{HPO}_{4}{ }^{2-}\right)$ ions, which can be used in a wide range of biological processes (cell division, growth, development, enzyme activation, etc.). ${ }^{54,55}$ In part, this difference between the calcium and phosphate ions in the non-implanted and implanted materials (inorganic) is captured by the first component of the PCA model. Additionally, the first component differentiates the presence or absence of an organic source, that is, implanted or not. If not used by cells, the calcium phosphate bioproducts can be offloaded and might re-precipitate into the most stable $\mathrm{CaP}$.

The ToF-SIMS analysis allowed us additionally to distinguish the overall tissue structure of the sample with similar morphological and compositional patterns, as described in histology. The histological analysis clearly showed the presence of the transformation of the $\mathrm{CaP}$ into a viable woven and lamellar bone. Additionally, it revealed the presence of different cells, osteoblasts, osteoclasts, osteocytes, and macrophages filled with the $\mathrm{CaP}$ material in the vicinity of the new bone-implant interface. ${ }^{2-4,6,8,22,25,42,43}$

Overall, ToF-SIMS offers a unique way of probing the cell content in situ in an explant, without any need for further sample preparation. Even though ToF-SIMS has been used to 
A

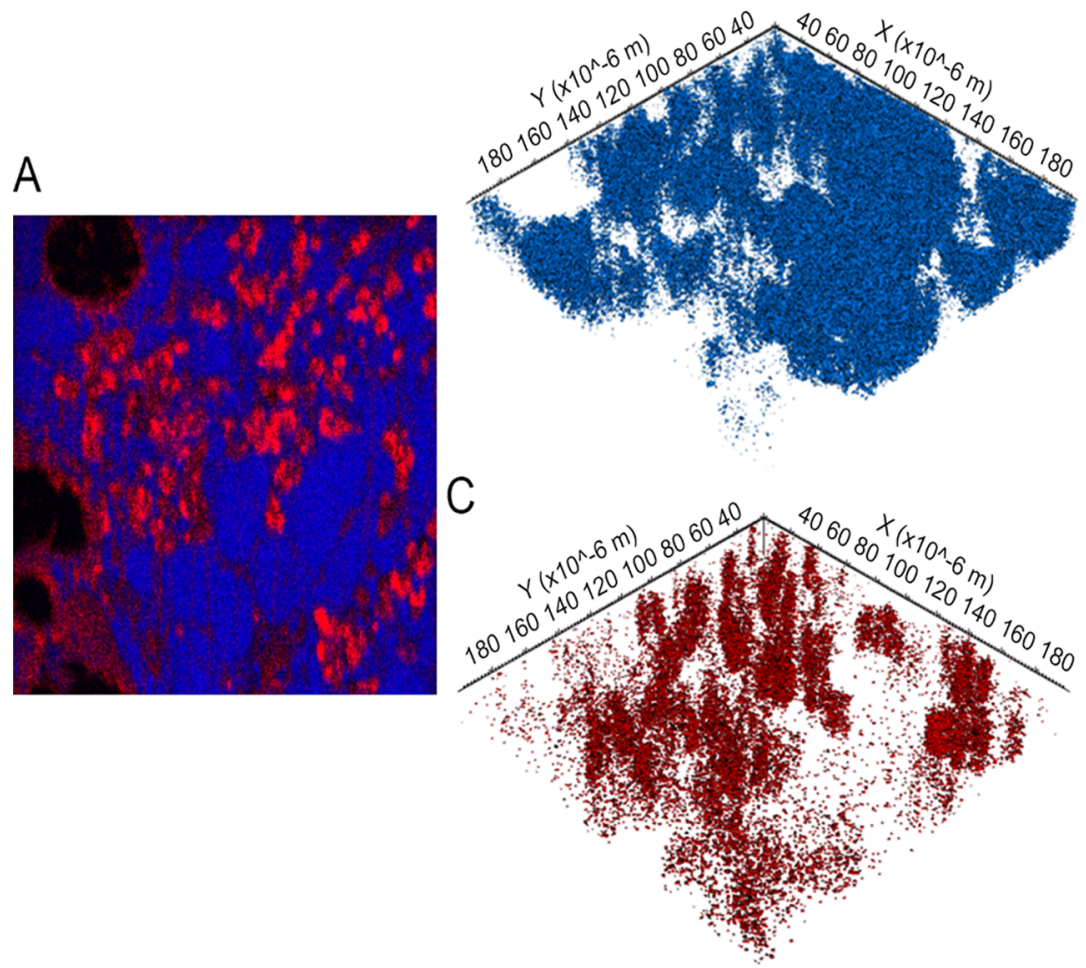

B
D

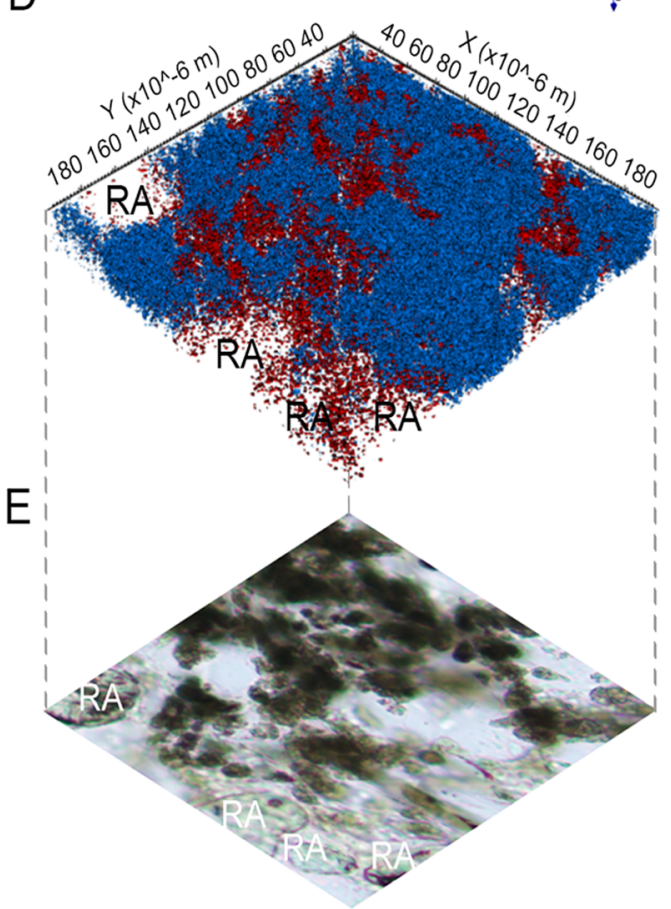

Figure 6. Distribution of $\mathrm{Ca}_{x} \mathrm{P}_{y}$ species in the ROI. (A) ToF-SIMS 2D image of the ROI containing macrophages showing the distribution of $\left[\mathrm{Ca}_{2} \mathrm{PO}_{4}\right]^{+}$and $\left[\mathrm{Ca}_{3} \mathrm{PO}_{5}\right]^{+}$in red and $\left[\mathrm{C}_{5} \mathrm{H}_{9}\right]^{+}$in blue. (B) ToF-SIMS 3D iso-surface renderings of the area with a general lipid signal from (B) $\mathrm{C}_{5} \mathrm{H}_{9}$ in blue and (C) $\mathrm{Ca}_{2} \mathrm{PO}_{4}$ in red. (D) $3 \mathrm{D}$ overlay showing the $3 \mathrm{D}$ distribution of $\mathrm{Ca}_{2} \mathrm{PO}_{4}$ in red and $\mathrm{C}_{5} \mathrm{H}_{9}$ in blue highlighting the distribution of the macrophage cell content in the depth of the cells matching with (E) unstained histology magnification. Depth of analysis is approx. $200 \mathrm{~nm}$. Acronym: RA: resin artifact.

probe cell content in cultured osteoblast-like cells, ${ }^{30}$ in bonebiomaterial interphases, ${ }^{56-31}$ and in other types of tissues such as muscle and lung biopsies, ${ }^{58}$ it has not yet been utilized to identify cell content in explants or implant surroundings.

One limitation of ToF-SIMS is that it is a surface-sensitive method, which requires pure samples without surface contamination. This can in part, as was done in this study, be addressed by depth profiling and 3D ToF-SIMS analysis, where chemical information from not only the surface but also the depth of a sample/cell is taken into account. The data obtained are analyzed semi-quantitatively with the need for multivariate analysis to interpret the data. However, ToF-SIMS can be used without any a priori knowledge of the sample or the need for any specific tissue and/or material stains or labels. Using labels always carries a risk that not only the structure and/or function of the material under study but also the fundamental biological answer is altered. Given the study aimed to investigate whether ToF-SIMS would allow for the identification of the macrophage content, known variabilities affecting bone metabolism, such as gender, health status, and age, ${ }^{59,60}$ were not taken into account. To the best of our knowledge, this study is the first to uncover the content of macrophages directly on a human explant.

Future studies should explore a wider range of calcium phosphate biomaterials to allow for both organic and inorganic target comparisons of various MFMs found in vivo. In addition, a larger sample size would allow for within and between cohort variations to be studied.

In summary, the $2 \mathrm{D} / 3 \mathrm{D}$ ToF-SIMS analysis of macrophages from a human cranial explant revealed $\beta$-CPP to be the main intracellular phase when exposed to a triphasic $\mathrm{CaP}$ material. Furthermore, the ToF-SIMS 3D analysis showed that the cell content was distributed throughout the whole of the macrophage, which ruled out the possibility of this being a surface phenomenon or an artifact of analyzing content outside the cells.

\section{CONCLUSIONS}

In this study, we demonstrate the feasibility to employ ToFSIMS to uncover human macrophage cellular content during material resorption. The combination of $2 \mathrm{D} / 3 \mathrm{D}$ ToF-SIMS and histology was applied to elucidate the distinct $\mathrm{CaP}$ phases in macrophages from a human multiphasic $\mathrm{CaP}$ explant, demonstrating pyrophosphate $(\beta$-CPP) to be the main phase present. The ability to distinguish and localize multiple $\mathrm{CaP}$ phases on an intracellular level opens up the possibilities to utilize ToF-SIMS as a powerful tool in cell-driven mechanistic studies.

\section{ASSOCIATED CONTENT}

\section{SI Supporting Information}

The Supporting Information is available free of charge at https://pubs.acs.org/doi/10.1021/acsabm.1c00513.

TOF-SIMS spectra from reference materials and implants; full results from a PCA analysis based on the positive ion-mode ToF-SIMS data; and complementary TOF-SIMS ion images (PDF) 


\section{AUTHOR INFORMATION}

\section{Corresponding Author}

Ulrik Birgersson - Department of Clinical Neuroscience, Neurosurgical Section, Karolinska University Hospital and Karolinska Institute, 17176 Stockholm, Sweden; Division of Imaging and Technology, Department of Clinical Science, Intervention and Technology, Karolinska Institute, 14152 Huddinge, Sweden; Email: ulrik.birgersson@ki.se

\section{Authors}

Per Malmberg - Department of Chemistry and Chemical Engineering, Chalmers University of Technology, 41296 Gothenburg, Sweden; ๑ orcid.org/0000-0002-6487-7851

Viviana R. Lopes - Science for Life Laboratory, Department of Medicinal Chemistry, Uppsala University, 75183 Uppsala, Sweden; $\odot$ orcid.org/0000-0003-2079-4170

Gry Hulsart Billström - Science for Life Laboratory, Department of Medicinal Chemistry, Uppsala University, 751 83 Uppsala, Sweden

Sara Gallinetti - Department of Engineering Sciences, Applied Materials Science Section, Uppsala University, 75121 Uppsala, Sweden

Christopher Illies - Department of Clinical Pathology, Karolinska University Hospital, 17177 Stockholm, Sweden

Lars Kihlström Burenstam Linder - Department of Clinical Neuroscience, Neurosurgical Section, Karolinska University Hospital and Karolinska Institute, 17176 Stockholm, Sweden

Complete contact information is available at: https://pubs.acs.org/10.1021/acsabm.1c00513

\section{Author Contributions}

The manuscript was written with the contributions of all authors. All authors have given approval to the final version of the manuscript.

\section{Funding}

The ToF-SIMS measurements were sponsored by OssDsign $A B$. No other specific grants from funding agencies in the public or not-for-profit sectors were received.

\section{Notes}

The authors declare the following competing financial interest(s): Per Malmberg and Christopher Illies declare no competing interests. Viviana R Lopes, Sara Gallinetti and Ulrik Birgersson are employed by OssDsign AB. Gry Hulsart Billstrom and Lars Kihlstrom Burenstam Linder serve as consultants with OssDsign $\mathrm{AB}$.

\section{REFERENCES}

(1) del Real, R. P.; Ooms, E.; Wolke, J. G. C.; Vallet-Regí, M.; Jansen, J. A. In vivobone response to porous calcium phosphate cement. J. Biomed. Mater. Res., Part A 2003, 65A, 30-36.

(2) Apelt, D.; Theiss, F.; El-Warrak, A. O.; Zlinszky, K.; BettschartWolfisberger, R.; Bohner, M.; Matter, S.; Auer, J. A.; von Rechenberg, B. In Vivo Behavior of Three Different Injectable Hydraulic Calcium Phosphate Cements. Biomaterials 2004, 25, 1439-1451.

(3) Theiss, F.; Apelt, D.; Brand, B.; Kutter, A.; Zlinszky, K.; Bohner, M.; Matter, S.; Frei, C.; Auer, J. A.; von Rechenberg, B. Biocompatibility and Resorption of a Brushite Calcium Phosphate Cement. Biomaterials 2005, 26, 4383-4394.

(4) Kuemmerle, J. M.; Oberle, A.; Oechslin, C.; Bohner, M.; Frei, C.; Boecken, I.; Rechenberg, B. v. Assessment of the Suitability of a New Brushite Calcium Phosphate Cement for Cranioplasty - An
Experimental Study in Sheep. J. Cranio-Maxillofacial Surg. 2005, 33, 37-44.

(5) Engstrand, T.; Kihlström, L.; Neovius, E.; Skogh, A.-C. D.; Lundgren, T. K.; Jacobsson, H.; Bohlin, J.; Åberg, J.; Engqvist, H. Development of a bioactive implant for repair and potential healing of cranial defects. J. Neurosurg. 2014, 120, 273-277.

(6) Kihlström Burenstam Linder, L.; Birgersson, U.; Lundgren, K.; Illies, C.; Engstrand, T. Patient-Specific Titanium-Reinforced Calcium Phosphate Implant for the Repair and Healing of Complex Cranial Defects. World Neurosurg. 2019, 122, e399-e407.

(7) Xu, H. H.; Wang, P.; Wang, L.; Bao, C.; Chen, Q.; Weir, M. D.; Chow, L. C.; Zhao, L.; Zhou, X.; Reynolds, M. A. Calcium Phosphate Cements for Bone Engineering and Their Biological Properties. Bone Res. 2017, 5, 1-19.

(8) Engstrand, T.; Kihlström, L.; Lundgren, K.; Trobos, M.; Engqvist, H.; Thomsen, P. Bioceramic Implant Induces Bone Healing of Cranial Defects. Plast. Reconstr. Surg. 2015, 3, No. e491.

(9) Großardt, C.; Ewald, A.; Grover, L. M.; Barralet, J. E.; Gbureck, U. Passive and Active in Vitro Resorption of Calcium and Magnesium Phosphate Cements by Osteoclastic Cells. Tissue Eng., Part A 2010, $16,3687-3695$

(10) Sheikh, Z.; Brooks, P.; Barzilay, O.; Fine, N.; Glogauer, M. Macrophages, Foreign Body Giant Cells and Their Response to Implantable Biomaterials. Materials 2015, 8, 5671-5701.

(11) Sheikh, Z.; Abdallah, M.-N.; Hanafi, A.; Misbahuddin, S.; Rashid, H.; Glogauer, M. Mechanisms of in Vivo Degradation and Resorption of Calcium Phosphate Based Biomaterials. Materials 2015, 8, 7913-7925.

(12) Bohner, M.; Miron, R. J. A Proposed Mechanism for MaterialInduced Heterotopic Ossification. Mater. Today 2019, 22, 132-141. (13) Heymann, D.; Pradal, G.; Benahmed, M. Cellular Mechanisms of Calcium Phosphate Ceramic Degradation. Histol. Histopathol. 1999, 14, 871-877.

(14) Salhotra, A.; Shah, H. N.; Levi, B.; Longaker, M. T. Mechanisms of Bone Development and Repair. Nat. Rev. Mol. Cell Biol. 2020, 21, 696-711.

(15) Gordon, S. Phagocytosis: An Immunobiologic Process. Immunity 2016, 44, 463-475.

(16) Chen, Z.; Klein, T.; Murray, R. Z.; Crawford, R.; Chang, J.; Wu, C.; Xiao, Y. Osteoimmunomodulation for the Development of Advanced Bone Biomaterials. Mater. Today 2016, 19, 304-321.

(17) Dong, L.; Wang, C. Harnessing the Power of Macrophages/ Monocytes for Enhanced Bone Tissue Engineering. Trends Biotechnol. 2013, 31, 342-346.

(18) Richards, D. M.; Endres, R. G. The Mechanism of Phagocytosis: Two Stages of Engulfment. Biophys. J. 2014, 107, $1542-1553$

(19) Li, M.; Guo, X.; Qi, W.; Wu, Z.; de Bruijn, J. D.; Xiao, Y.; Bao, C.; Yuan, H. Macrophage Polarization Plays Roles in Bone Formation Instructed by Calcium Phosphate Ceramics. J. Mater. Chem. B 2020, 8, 1863-1877.

(20) Xia, Z.; Triffitt, J. T. A Review on Macrophage Responses to Biomaterials. Biomed. Mater. 2006, 1, R1-R9.

(21) Arango Duque, G.; Descoteaux, A. Macrophages Tell the NonProfessionals What to Do. Dev. Cell 2016, 39, 633-635.

(22) Gallinetti, S.; Linder, L. K. B.; Åberg, J.; Illies, C.; Engqvist, H.; Birgersson, U. Titanium reinforced calcium phosphate improves bone formation and osteointegration in ovine calvaria defects: a comparative 52 weeks study. Biomed. Mater. 2021, 16, 035031.

(23) Khashaba, R. M.; Moussa, M. M.; Mettenburg, D. J.; Rueggeberg, F. A.; Chutkan, N. B.; Borke, J. L. Polymeric-Calcium Phosphate Cement Composites-Material Properties:In VitroandIn VivoInvestigations. Int. J. Biomater. 2010, 2010, 1-14.

(24) Lewin, S.; Kihlström Burenstam Linder, L.; Birgersson, U.; Gallinetti, S.; Åberg, J.; Engqvist, H.; Persson, C.; Öhman-Mägi, C. Monetite-Based Composite Cranial Implants Demonstrate LongTerm Clinical Volumetric Balance by Concomitant Bone Formation and Degradation. Acta Biomater. 2021, 128, 502-513. 
(25) Omar, O.; Engstrand, T.; Kihlström Burenstam Linder, L.; Åberg, J.; Shah, F. A.; Palmquist, A.; Birgersson, U.; Elgali, I.; PujariPalmer, M.; Engqvist, H.; Thomsen, P. In Situ Bone Regeneration of Large Cranial Defects Using Synthetic Ceramic Implants with a Tailored Composition and Design. Proc. Natl. Acad. Sci. 2020, 117, 26660-26671.

(26) Miron, R. J.; Bosshardt, D. D. OsteoMacs: Key players around bone biomaterials. Biomaterials 2016, 82, 1-19.

(27) Chang, M. K.; Raggatt, L.-J.; Alexander, K. A.; Kuliwaba, J. S.; Fazzalari, N. L.; Schroder, K.; Maylin, E. R.; Ripoll, V. M.; Hume, D. A.; Pettit, A. R. Osteal Tissue Macrophages Are Intercalated throughout Human and Mouse Bone Lining Tissues and Regulate Osteoblast Function In Vitro and In Vivo. J. Immunol. 2008, 181, $1232-1244$

(28) Kleine-Boymann, M.; Rohnke, M.; Henss, A.; Peppler, K.; Sann, J.; Janek, J. Discrimination between Biologically Relevant Calcium Phosphate Phases by Surface-Analytical Techniques. Appl. Surf. Sci. 2014, 309, 27-32.

(29) Chusuei, C. C.; Goodman, D. W.; van Stipdonk, M. J.; Justes, D. R.; Schweikert, E. A. Calcium Phosphate Phase Identification Using XPS and Time-of-Flight Cluster SIMS. Anal. Chem. 1999, 71, 149-153.

(30) Kokesch-Himmelreich, J.; Schumacher, M.; Rohnke, M.; Gelinsky, M.; Janek, J. ToF-SIMS Analysis of Osteoblast-like Cells and Their Mineralized Extracellular Matrix on Strontium Enriched Bone Cements. Biointerphases 2013, 8, 17.

(31) Eriksson, C.; Malmberg, P.; Nygren, H. Time-of-Flight Secondary Ion Mass Spectrometric Analysis of the Interface between Bone and Titanium Implants. Rapid Commun. Mass Spectrom. 2008, 22, 943-949.

(32) Malmberg, P.; Bexell, U.; Eriksson, C.; Nygren, H.; Richter, K. Analysis of Bone Minerals by Time-of-Flight Secondary Ion Mass Spectrometry: A Comparative Study Using Monoatomic and Cluster Ions Sources. Rapid Commun. Mass Spectrom. 2007, 21, 745-749.

(33) Mukherjee, S. P.; Lazzaretto, B.; Hultenby, K.; Newman, L.; Rodrigues, A. F.; Lozano, N.; Kostarelos, K.; Malmberg, P.; Fadeel, B. Graphene Oxide Elicits Membrane Lipid Changes and Neutrophil Extracellular Trap Formation. Chem 2018, 4, 334-358.

(34) Henss, A.; Otto, S.-K.; Schaepe, K.; Pauksch, L.; Lips, K. S.; Rohnke, M. High Resolution Imaging and 3D Analysis of Ag Nanoparticles in Cells with ToF-SIMS and Delayed Extraction. Biointerphases 2018, 13, 03B410.

(35) Najafinobar, N.; Venkatesan, S.; von Sydow, L.; Klarqvist, M.; Olsson, H.; Zhou, X.-H.; Cloonan, S. M.; Malmberg, P. ToF-SIMS Mediated Analysis of Human Lung Tissue Reveals Increased Iron Deposition in COPD (GOLD IV) Patients. Sci. Rep. 2019, 9, 10060.

(36) Doebelin, N.; Kleeberg, R. Profex: a graphical user interface for the Rietveld refinement programBGMN. J. Appl. Crystallogr. 2015, 48, $1573-1580$

(37) Boudin, S.; Grandin, A.; Borel, M. M.; Leclaire, A.; Raveau, B. Redetermination of the $\beta$-Ca2P2O7 structure. Acta Crystallogr., Sect. C: Cryst. Struct. Commun. 1993, 49, 2062-2064.

(38) Dickens, B.; Schroeder, L. W.; Brown, W. E. Crystallographic studies of the role of $\mathrm{Mg}$ as a stabilizing impurity in $\beta$-Ca3(PO4)2. The crystal structure of pure $\beta$-Ca3(PO4)2. J. Solid State Chem. 1974, 10, 232-248.

(39) Dickens, B.; Bowen, J. S.; Brown, W. E. A Refinement of the Crystal Structure of CaHPO4 (Synthetic Monetite). Acta Crystallogr., Sect. B: Struct. Crystallogr. Cryst. Chem. 1972, 28, 797-806.

(40) Sodhi, R. N. S. Time-of-flight secondary ion mass spectrometry (TOF-SIMS):-versatility in chemical and imaging surface analysis. Analyst 2004, 129, 483-487.

(41) Vanbellingen, Q. P.; Elie, N.; Eller, M. J.; Della-Negra, S.; Touboul, D.; Brunelle, A. Time-of-flight secondary ion mass spectrometry imaging of biological samples with delayed extraction for high mass and high spatial resolutions. Rapid Commun. Mass Spectrom. 2015, 29, 1187-1195.

(42) Constantz, B. R.; Barr, B. M.; Ison, I. C.; Fulmer, M. T.; Baker, J.; McKinney, L.; Goodman, S. B.; Gunasekaren, S.; Delaney, D. C.;
Ross, J.; Poser, R. D. Histological, Chemical, and Crystallographic Analysis of Four Calcium Phosphate Cements in Different Rabbit Osseous Sites. J. Biomed. Mater. Res. 1998, 43, 451-461.

(43) Bohner, M.; Theiss, F.; Apelt, D.; Hirsiger, W.; Houriet, R.; Rizzoli, G.; Gnos, E.; Frei, C.; Auer, J. A.; von Rechenberg, B. Compositional Changes of a Dicalcium Phosphate Dihydrate Cement after Implantation in Sheep. Biomaterials 2003, 24, 3463-3474.

(44) Sundblom, J.; Xheka, F.; Casar-Borota, O.; Ryttlefors, M. Bone Formation in Custom-Made Cranioplasty: Evidence of Early and Sustained Bone Development in Bioceramic Calcium Phosphate Implants. Patient Series. J. Neurosurg. 2021, 1(17), CASE20133. DOI: $10.3171 / C A S E 20133$.

(45) Vereecke, G.; Lemaitre, J. Calculation of the Solubility Diagrams in the System $\mathrm{Ca}(\mathrm{OH}) 2-\mathrm{H} 3 \mathrm{PO} 4-\mathrm{KOH}-\mathrm{HNO} 3-\mathrm{CO} 2-$ H2O. J. Cryst. Growth 1990, 104, 820-832.

(46) Pritzker, K. P. H. Articular Pathology of Gout, Calcium Pyrophosphate Dihydrate and Basic Calcium Phosphate Crystal Deposition Arthropathies. Gout \& Other Crystal Arthropathies; Elsevier, 2012

(47) $\mathrm{Wu}, \mathrm{V} . \mathrm{M}$.; Uskoković, V. Is there a relationship between solubility and resorbability of different calcium phosphate phases in vitro ? Biochim. Biophys. Acta, Gen. Subj. 2016, 1860, 2157-2168.

(48) Yao, Y.; Zhang, H.; Wang, Z.; Ding, J.; Wang, S.; Huang, B.; Ke, S.; Gao, C. Reactive Oxygen Species (ROS)-Responsive Biomaterials Mediate Tissue Microenvironments and Tissue Regeneration. J. Mater. Chem. B 2019, 7, 5019-5037.

(49) Canton, J.; Khezri, R.; Glogauer, M.; Grinstein, S. Contrasting Phagosome PH Regulation and Maturation in Human M1 and M2 Macrophages. Mol. Biol. Cell 2014, 25, 3330-3341.

(50) Lee, H.-B.; Hsu, H.-C.; Wu, S.-C.; Hsu, S.-K.; Wang, P.-H.; Ho, W.-F. Microstructure and Characteristics of Calcium Phosphate Layers on Bioactive Oxide Surfaces of Air-Sintered Titanium Foams after Immersion in Simulated Body Fluid. Materials 2016, 9, 956.

(51) Canton, J. Phagosome Maturation in Polarized Macrophages. J. Leukocyte Biol. 2014, 96, 729-738.

(52) C. Chow, L. Next Generation Calcium Phosphate-Based Biomaterials. Dent. Mater. J. 2009, 28, 1-10.

(53) Zent, C. S.; Elliott, M. R. Maxed out Macs: Physiologic Cell Clearance as a Function of Macrophage Phagocytic Capacity. FEBS J. 2017, 284, 1021-1039.

(54) Beck, L.; Beck-Cormier, S. Extracellular Phosphate Sensing in Mammals: What Do We Know? J. Mol. Endocrinol. 2020, 65, R53R63.

(55) Krebs, J. Calcium Biochemistry. Encyclopedia of Molecular Cell Biology and Molecular Medicine; Wiley-VCH Verlag GmbH \& Co. KGaA: Weinheim, Germany, 2006.

(56) Schaepe, K.; Bhandari, D. R.; Werner, J.; Henss, A.; Pirkl, A.; Kleine-Boymann, M.; Rohnke, M.; Wenisch, S.; Neumann, E.; Janek, J.; Spengler, B. Imaging of Lipids in Native Human Bone Sections Using TOF-Secondary Ion Mass Spectrometry, Atmospheric Pressure Scanning Microprobe Matrix-Assisted Laser Desorption/Ionization Orbitrap Mass Spectrometry, and Orbitrap-Secondary Ion Mass Spectrometry. Anal. Chem. 2018, 90, 8856-8864.

(57) Palmquist, A.; Emanuelsson, L.; Sjövall, P. Chemical and Structural Analysis of the Bone-Implant Interface by TOF-SIMS, SEM, FIB and TEM: Experimental Study in Animal. Appl. Surf. Sci. 2012, 258, 6485-6494.

(58) Malmberg, P.; Jennische, E.; Nilsson, D.; Nygren, H. HighResolution, Imaging TOF-SIMS: Novel Applications in Medical Research. Anal. Bioanal. Chem. 2011, 399, 2711-2718.

(59) Schiellerup, S. P.; Skov-Jeppesen, K.; Windeløv, J. A.; Svane, M. S.; Holst, J. J.; Hartmann, B.; Rosenkilde, M. M. Gut Hormones and Their Effect on Bone Metabolism. Potential Drug Therapies in Future Osteoporosis Treatment. Front. Endocrinol. 2019, 10, 75.

(60) Cauley, J. A. Estrogen and Bone Health in Men and Women. Steroids 2015, 99, 11-15. 